\title{
Sometimes spelling is easier than phonemic segmentation
}

\author{
WIM H. J. van BON and HERMIEN C. M. DUIGHUISEN \\ Department of Special Education, University of Nijmegen, Nijmegen, The Netherlands
}

van Bon, W. H. J. \& Duighuisen, H. C. M. (1994). Sometimes spelling is easier than phonemic segmentation. Scandinavian Journal of Psychology, 36, 82-94.

\begin{abstract}
Poor spellers from the Netherlands segmented and spelled the same words on different occasions. If they base their spellings on the segmentations that they produce in the segmentation task, the correlation between segmentation and spelling scores should be high, and segmentation should not be more difficult than spelling. The predicted correlation was found, but spelling proved to be easier than segmentation, particularly for postvocalic consonant-clusters. Correct spellings despite incorrect segmentation were also more frequent than would be expected on the basis of unreliability of segmentation. Ways in which writing may facilitate and improve segmentation are therefore discussed. These findings raise doubts about the validity of segmentation test and about the efficiency of teaching children to segment without using letters.
\end{abstract}

Key words: Phonemic segmentation, spelling, spelling problems, school age children, phonology.

Wim H. J. van Bon, Department of Special Education, University of Nijmegen, Nijmegen, The Netherlands

A great deal of research has been devoted to the relation between reading and phonemic segmentation, that is the ability to divide spoken words into their component speech sounds. The basic view underlying these investigations is that at some point in the process of learning to read the child should understand and learn to follow the phonological decoding principle. Learning to read, therefore, demands that the child becomes aware of the composite character of the spoken word in order to understand the nature and the operation of grapheme-phoneme conversion rules. As expected, a strong relationship has been established between phonemic analysis tasks and reading ability (e.g. Calfee et al., 1973; Fox \& Routh, 1975; Helfgott, 1976; Lundberg et al., 1980; Stanovich et al., 1984).

An even stronger relationship can be expected to exist between phonemic segmentation ability and spelling. We will leave the arguments aside that can be derived from the supposition that writing draws upon alphabetic routines at earlier stages of development than reading (Frith, 1985), because it is highly probable that an initial prolonged use of nonalphabetic, logographic routines for reading will only be found in languages with a deep and opaque orthography (Wimmer \& Hummer, 1990). Our expectation, rather, stems from the observation that dual or plural route models of spelling always include segmentation processes operating on the spoken word whereas segmentation processes in comparable reading models operate on letter strings rather than on spoken word forms. In this respect the reading and the writing model outlined by Ellis (1984) can be considered as exemplary. The reading model is basically Coltheart's (1978) dual route model and postulates two main procedures for the recognition and naming of written words. One procedure uses the lexical knowledge of word specific orthographic patterns. The other involves putting together the phonemic units that result from the application of grapheme-phoneme conversion rules. Even along this phonologically mediated route, however, phonemic segmentation of the spoken word is not required. The spelling model also has two main routes. One involves the 
retrieval of knowledge about word-specific orthographic patterns. The other implies the application of phoneme-grapheme conversion rules to the phonemic segments of the spoken word to be written. So, while the phonological route in writing entails phonemic segmentation, the phonological route in reading requires the opposite, namely synthesis or blending of phonological units. There is indeed some evidence that reading requires synthesis rather than segmentation (Perfetti et al., 1987) and that segmentation skill is more closely related to spelling than to reading ability (Cataldo \& Ellis, 1988; Perin, 1983).

The point we want to stress here is that, whereas phonemic segmentation skills are required in order to understand the basic alphabetic principles of reading and writing, it is in spelling rather than in reading that the effects of the way in which spoken words are segmented are likely to be found. For this implicit reason, perhaps, the correspondence between the way in which words are read and the way they are segmented has never been examined.

Attempts to relate spelling of the individual word to the way in which the phonemic make-up of the spoken word is conceptualized by the writer have been made, however. For instance, the studies by Read (1971, 1986) and by others (Chomsky, 1979; Mann et al., 1987; Treiman, 1985b) on invented spellings are well known. Consistent deviations in the invented spellings from the standard spellings are assumed to reflect the way in which children conceive the phonologically structure of the relevant words. Another approach, and that which is taken here, is to consider the segments produced when partitioning the spoken word in a segmentation task as the hypothetical basis for the spelling of that word. If one is interested in the way children conceptualize the phonological structure of a word that they are going to write, asking them about the speech sounds that make up the word-with $b-u-s$ as the correct representation for bus, for example-is an obvious means to employ. A prerequisite for such use of a segmentation task, however, is that it should be possible to show that there is a correspondence between segmentation and spelling product. Verifying this correspondence is a goal of this study. Evidence in favor of the segmentation task is provided by Treiman (1985b). Instead of requiring full segmentation of the words, however, she asked children to judge whether they began with a particular speech sound and was then able to show that nonstandard judgments of these speech sounds were also reflected in these children's spellings. Doubts about the validity of the segmentation tasks have been raised, however, by Tunmer and Nesdale (1982). Arguing that this task requires the production of segments that differ from their counterparts in the spoken words, they prefer the phoneme tapping task developed by Liberman (1973). Schreuder and van Bon (1989) pointed out, however, that a number of important questions about phonemic insight cannot be answered using the tappping task. The task gives no information about the way in which individual segments are classified by subjects. It also does not tell us about segmentation errors that leave the total number of phonemes correct (e.g., segmenting mist into $m-i-s-t$ ). Schreuder and van Bon also found it questionable whether the relation between taps and phonemes is indeed of a less abstract nature than that between phonemes and the sounds produced in the segmentation task. An empirical argument against giving up the segmentation task for a tapping task can be derived from Yopp (1988). The two tasks had comparable factor loadings and correlated equally with novel word reading. A stronger case for the phonemic segmentation test could be made, however, if a correspondence between segmentation and spelling behaviour could be demonstrated. To the degree that such a correspondence exists, the phonemic segmentation test can be assumed to be a valid indicator of the phonological insight that the writer brings to the spelling task. Negative findings would suggest that the segmentation test does not give a veridical portrayal of the way in which a child segments a word when spelling or that spelling is brought about by procedures that do not involve phonemic segmentation. 
In the phonemic segmentation task subjects are required to do what novice spellers are frequently observed to do along with expert spellers writing complex words: say the segments of a word that has to be written down. Differences between the spelling and segmentation tasks, however, may affect the validity of the segmentation task in revealing the phoneme identification skill underlying spelling performance. For instance, even in beginning spelling overt pronouncing is more likely extraneous to the task, and at best a concomittant with a supporting function. Moreover, if phoneme-grapheme correspondence rules are applied to abstract phonemes, pronouncing them in the segmentation task would ask for additional operations that are not required in spelling. Also, in actual spelling the hypothesized segmentation process will be supplemented with spelling-specific routines for grapheme selection and production that might influence the segmentation process.

For subjects who are likely to follow an alphabetic strategy in spelling, the assumption that the segmentation task gives a valid characterization of the segmentation involved in spelling would not only predict a high correlation between segmentation and spelling of the same words, but also that 1) segmentation should not be more difficult than spelling, and 2) correct spelling of incorrectly segmented words should not occur. Because correct segmentation is supposed to be a necessary but not sufficient prerequisite for correct spelling, spelling errors might outnumber segmentation errors.

Most theories of spelling development (e.g., Beers, 1980; Ellis, 1984; Frith, 1985; Marsh et al., 1980) state that at early stages children spell by means of an alphabetic strategy such as the one sketched above, which involves phonemic segmentation. At a later stage this strategy supposedly gives way to one using word-specific orthographic knowledge, but remains available for writing unknown or forgotten words. The feasibility of an alphabetic strategy is highest if the language is characterized by a good fit between phonological and graphemic representations and teaching emphasizes a phonic approach. The orthography of Dutch, the language used in this study, is indeed basically transparent (see van Heuyen, 1980, for an outline and further references). All monosyllabic words that are not loan words can be correctly read by applying simple grapheme-phoneme conversion rules, although some phonemes are represented by multiletter graphemes. In writing these words, some ambiguity may arise because certain phonemes have homophonic spellings, but the large majority of the phonemes can be spelled correctly by straightforward phoneme-grapheme conversion. The spelling of polysyllabic words is also largely rule-governed. In early stages of teaching Dutch reading and spelling, therefore, emphasis is on phonological skills with only a marginal role for learning sight words. These circumstances favor the early use of alphabetic strategies, and if indications of phonological spelling such as evidenced by a correspondence between segmentation and spelling errors are to be found, then they should be found in Dutch children who are just beginning to read and write or who are arrested in an early phase of the learning process.

In a preliminary study of children following approximately three months of formal reading and spelling education in elementary schools (Duighuisen et al., 1990), it was found that the segmentation and the spelling of CVCCs ( $C$ stands for consonant, V for vowel) correlated highly, but that segmentation was significantly more difficult than spelling. A considerable number of words were spelled well but segmented incorrectly. Apart from the doubt that this outcome throws on the assumption that children spell phonologically and on the validity of the segmentation task used, the question arises to what proportion the discordance between segmentation and spelling can be explained from their unreliability, i.e. the unstability of segmentation and spelling from one occassion to the other. The purpose of the present experiment, therefore, was to replicate this earlier study and to determine test-retest reliability. Children who are backward in spelling were chosen as subjects because of the common 
diagnostic practice to draw inferences about the nature of children's spelling problems from their segmentation test performance. Spelling problems associated with poor segmentation test scores might, thus, lead to prescribing segmentation training. A discrepancy between spelling and segmentation performance as was found before, and poor test-retest reliability, however, would seriously question the appropriateness of this practice.

\section{METHODS}

\section{Subjects}

Forty-two students were selected from three schools for children with leaming disabilities in the Netherlands. Children generally are admitted to these special schools because of large discrepancies between their scholastic achievement and their intelligence. No severe conduct disorders or physical defects were reported that might be responsible for their discrepancies. The children came mostly from low and middle socio-economic backgrounds. Children were selected who according to their teachers were backward in spelling and had problems in spelling regular monosyllabic words. The ratio between the number of boys and girls (33:9) corresponds to that normally found in these schools. Their mean age was $8 ; 2$ (SD $0 ; 10)$. On the average, they had received 14 months of formal reading-spelling instruction with teaching methods emphasizing phonics. For practical reasons, it was not feasible to administer an intelligence test or standardized reading and spelling tests. From common admission practice, however, it can be inferred that the IQs of the children were above 85. Their spelling of the CVCCs and CCVCs in this experiment was only slightly better ( $73 \%$ correct) than that of a representative sample of Dutch children after only six months of spelling education ( $69 \%$ correct) writing the same word-types in the standardization study of a spelling test (Verhoeven, 1980a). Another indication that our sample was behind in spelling, is that the subjects in the present experiment wrote $50 \%$ of the CCVCCs correctly whereas $80 \%$ of the CCVCCs used in another standardized spelling test were written correctly by the standardization sample of children from elementary schools after one year of spelling education (Verhoeven, 1980b).

\section{Materials}

In the segmentation and spelling tests the same words were used, most of them nouns: 8 CVCs, 7 CCVCs, $1 \mathrm{CCV}, 8 \mathrm{CVCCs}$ and $8 \mathrm{CCVCCs}$ (see Appendix). All words can be written according to simple, context-free phoneme-grapheme conversion rules. No words were used containing phonemes with more than one common orthographic representation. Within these restrictions items were selected in such a way that the initial consonant clusters of $\operatorname{CCV}(\mathrm{C}) \mathrm{s}$ and final clusters of CVCCs were identical to the corresponding clusters of CCVCCs in order to maximize between-word-type comparability. An effort was made to distribute the different vowels and solitary consonants equally across the words. Consonant clusters were selected such that the probability of segmentation and spelling errors was maximal. Consonant digraphs (-ng, -ch-)and heterogeneous vowel digraphs (e.g., ui, oe, au) were not used in order to avoid inflation of spelling errors that cannot be ascribed to phonological factors (e.g., letter omissions or reversals). All of the words were assumed to be meaningful to the children of this age. Even the six words that were not included in the corpus of 202,526 tokens sampled from Dutch texts written for independent reading by 7- to 12-year-olds (Staphorius et al., 1989) can be supposed to be understood by the subjects. The words, however, do not stand out in the reading and spelling methods, e.g., are not sight words.

The 32 words were presented in a segmentation task that required children to name the phonemes of each word, thus to segment taart [cake] into $t-a a-r-t$, as they are accustomed to do. Each word was first presented in a sentence specifying its meaning and syntactic class, for example, Hij eet een stuk taart [He eats a piece of cake]. Then it was repeated alone, with the instruction to say the "little parts" of the word. There were three practice trials. It was stressed, initially, and if a response contained a cluster of speech sounds, that the "little parts" had to be said wide apart. Segmentation sessions were tape recorded for later analysis. In our experience, children at this educational level generally understand what they are required to do as segmentation tasks are part of the prevailing methods for teaching reading and is a standard exercise in literacy education in schools for learning disabled children.

The same words were also presented in a spelling task. They were dictated as in the segmentation task, using the same sentences, but now the target words had to be written down. The children were instructed to use a dash for any letter that they did not know. 


\section{Procedure}

Each test was administered twice for determining test-retest reliability. In order to balance the effect of segmentation on spelling and vice versa, four presentation orders were specified according to a latin square. Children were assigned randomly to one of the presentation orders. The spelling test was administered groupwise to as many of the selected children of a school as could be gathered at the same time. The segmentation test was administered individually. The segmentation test took about 10 minutes, the spelling test about 15 minutes. The interval between tests was a few hours to two days. The same test was never administered twice on the same day. The same random word order was used for both tests.

\section{RESULTS}

The design of the experiment permits the calculation of four segmentation-spelling correlation coefficients: first segmentation by first spelling, second segmentation by first spelling, etc. Only one segmentation and one spelling score was used, however. For half of the subjects, spelling scores and segmentation scores were from the first test administration. For the other subjects the data were from the second test administration. In the subsequent analyses at the word level, the corresponding item information from these same tests were used.

Across word types, the correlation between segmentation and spelling appears to be very high, 0.73 , as would be expected if spelling is based on the segments that are produced in the segmentation task. The prediction that segmentation would not be more difficult than spelling was also borne out by the data as spelling is more difficult than segmentation $(t(41)=1.98$, $p<0.05$ ). On the average, $68 \%$ were spelled correctly, while $73 \%$ of the words were segmented correctly. The more stringent prediction, however, that incorrectly segmented words should not be spelled well, was not corroborated by the results. As indicated by Table 1.1, the subjects on averaged spelled 3.1 words well that they segmented wrong in another testing session. This number is sigificantly larger than $0(t(41)=7.00 ; p<0.01)$, which shows that students are able to write words that are too difficult to segment. From the fact that spelling is more difficult than segmentation, it follows that the mean number of words that are incorrectly spelled despite a correct segmentation must be larger than the mean number of words that are spelled well despite an incorrect segmentation. The $t$-test results, of course, are the same as those of the spelling-segmentation difference discussed earlier. From this difference it can be deduced, 1) that the two kinds of discrepancies between spelling and segmentation do not have the same origin, for example test unreliability, and 2) that, even if segmentation underlies spelling, there is more to the spelling task than segmentation alone.

Table 1. Cross-tabulation of word segmentation and spelling: Mean number of words (and standard deviations) per subject $(n=42)$

\begin{tabular}{|c|c|c|c|c|}
\hline & & \multicolumn{3}{|c|}{ Segmentation } \\
\hline & & Incorrect & Correct & Total \\
\hline \multicolumn{5}{|c|}{ 1. Standard spelling criterion } \\
\hline Spelling & $\begin{array}{l}\text { Incorrect } \\
\text { Correct } \\
\text { Total }\end{array}$ & $\begin{array}{l}5.41(5.79) \\
3.14(2.91) \\
8.55(7.46)\end{array}$ & $\begin{array}{r}4.71(3.15) \\
18.74(7.21) \\
23.45(7.46)\end{array}$ & $\begin{array}{c}10.12(6.17) \\
21.88(6.17) \\
32\end{array}$ \\
\hline \multicolumn{5}{|c|}{ 2. Revised spelling criterion } \\
\hline Spelling & $\begin{array}{l}\text { Incorrect } \\
\text { Correct } \\
\text { Total }\end{array}$ & $\begin{array}{l}4.95(5.47) \\
3.60(3.34) \\
8.55(7.46)\end{array}$ & $\begin{array}{r}2.76(2.30) \\
20.69(7.60) \\
23.45(7.46)\end{array}$ & $\begin{array}{r}7.71(5.95) \\
24.29(5.95) \\
32\end{array}$ \\
\hline
\end{tabular}


The differences in performance on the segmentation and spelling task were perhaps amplified by different judgement criteria in the two tasks. In Dutch, a number of words are spelled with one vowel grapheme but often pronounced as two syllables. These are words with a postvocalic consonant cluster consisting of a liquid followed by another consonant that is not an $s$ or $t$. In pronouncing these words an unstressed neutral vowel (schwa) is often inserted between the two consonants. Our material contained four such words (werp, half, slurp, twaalf). A spelling containing a representation of this schwa was considered wrong as it deviates from the standard spelling while a segmentation containing a schwa wasn't, because such a segmentation corresponds to a common conception of the word's phonological make-up. In addition, the voiced-voiceless distinction underlying spellings with $z$ or $s$ and $v$ of $f$ in word-initial position seems gradually to be replaced by a pronunciation in which only the voiceless variants can be observed (Gussenhoven \& Bremmer, 1983). Moreover, in judging the segmentations it was usually impossible to decide whether a fricative was intended to be voiced or voiceless. Therefore, segmentations containing $f$ - or $s$-like sounds where the written word has $v$ or $z$ (and the hypercorrect reverse: saying $z$ or $v$ instead of $s$ or $f$ ) had not been counted as segmentation errors. Nonstandards $f s$ or $s s$ in the written words, however, were considered to be errors. Application of the more lenient segmentation scoring criteria to the spellings - while allowing for a few letter reversals as they were most likely not the result of segmentation errors - produced the results presented in Table 1.2. As can be seen, spelling now appears to be easier than segmentation, although not significantly, than segmentation, $76 \%$ versus $73 \%$ correct. As a consequence there are even more words spelled well that were segmented incorrectly, 3.6. Nearly half of the erroneously segmented words $(42 \%)$ are now considered well written.

As stated before, this divergence between segmentation and spelling might also occur if the way in which a word is segmented varies from one occasion to the other. Although the test-retest reliability of the segmentation test sum scores is very high, 0.92 , no exact inferences can be made about response stability at the item level. Comparing the segmentation of the individual words from the two-segmentation sessions, however, shows that on the average 4.2 of the 32 words were segmented differently on the two occasions (i.e. accurate on one occasion and inaccurate on the other). This gives an estimate of 2.1 correct spellings despite wrong segmentation because of the unreliability of segmentation. The actual number of such discrepancies (3.6), however, was significantly higher than that $(t(41)=2.93$, $p<0.01$ ), which suggests that other factors than instability of the segmentation are required for explaining the discrepancy between segmentation and spelling.

\section{DISCUSSION}

A number of findings in this study are in accordance with the assumption that the segmentation task performance validly indicates the segmentation skills that are supposed to underlie spelling in the early stages. The correlation between the segmentation and spelling test scores was high. Spelling test scores were generally no better than the segmentation test scores; and, at the word level a correct or incorrect segementation was often accompanied by a correct or incorrect spelling, respectively. Nevertheless, many words were also spelled correctly despite erroneous segmentation, and this holds even when allowance has been made for the instability of word segmentation.

There are some explanations for these unexpected correct spellings. The first is that our subjects knew the orthographic form of some words and therefore spelled them in a direct way which requires no phonemic decomposition. The words used in our study, however, while probably familiar in their spoken forms, will not have been often seen in their written 
forms. An experiment of Reitsma (1983), moreover, suggests that the learning of word specific orthographic patterns even by older students at special schools for learning disabled children requires that they read these words much more often than normal children. This argument is supported by the fact that word spelling difficulty in the present experiment does not appear to be related to the frequency of the words in the Staphorsius et al. (1989) corpus (Spearman Rho $=0.10$ ). Moreover, the segmentation errors do not show the effects of orthographic knowledge as no influence of spelling patterns on segmentation responses is found, such as naming the individual letters of the vowel digraphs in boot or zeep. Such effects would be expected from the finding that knowledge of the orthographic form of a word influences intuitions about that word's phonological form (Ehri \& Wilce, 1980; Tunmer \& Nesdale, 1982).

The second explanation has to do with the permanence of the written word. Writing down the word's segments helps to keep track of one's place in the word that is to be segmented. The graphemes that are jotted down to represent the phonemes that have already been identified, can be used for finding the point of departure for the next segmentation cycle. Systematically writing down the phonemes that are already identified would result in an unburdening of working memory, but because the information to be remembered is likely to increase as segmentation of the word progresses, the facilitating effect should be larger at the end than at the beginning of a word. This latter prediction was tested by comparing segmentation and spelling of the first versus the last consonants. Fig. 1 depicts the relevant results.

A repeated measured analysis of variance was done with number of consonants (single or cluster), position (initial or final), and task (segmentation or spelling) as within-subjects factors and proportion correct as the dependent variable. The number by position interaction was significant $(F(1,41)=37.09, p<0.01)$ and so was the task by position interaction $(F(1,41)=14.62, p<0.01)$. Other interactions were not significant. Main effects of number of consonants, position, and task were also significant $(F(1,41)=41.32, p<0.01$, $F(1,41)=43.06, p<0.01, F(1,41)=5.02, p<0.01$, respectively).

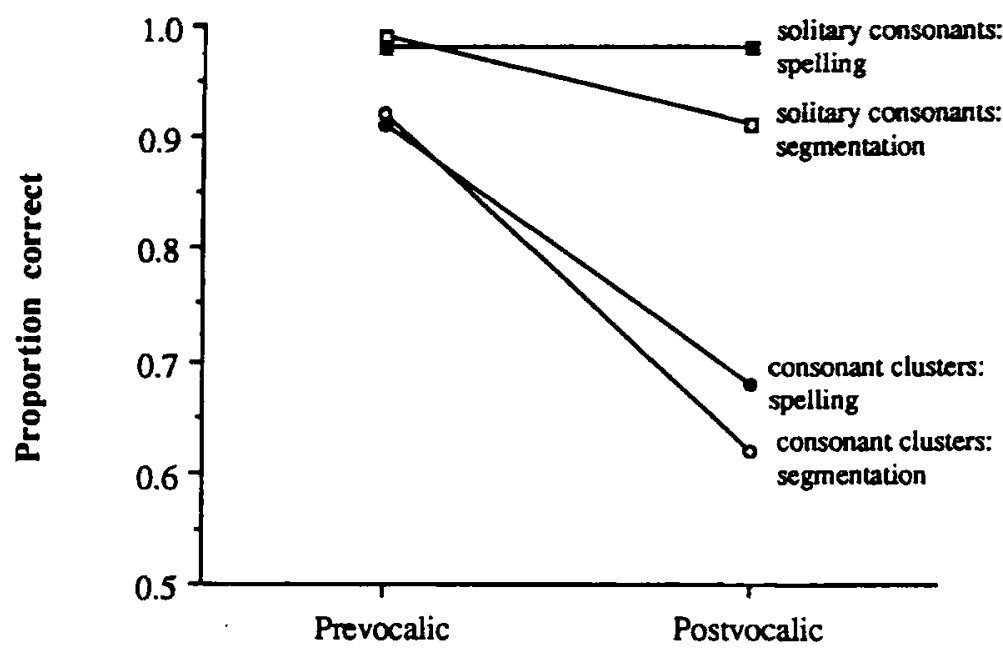

Position

Fig. 1. Proportion correct in relation to consonant position, number of consonants, and type of task. 
Testing the simple effects in the interactions show that segmentation of initial (prevocalic) consonants indeed is easier than that of final (postvocalic) consonants. This applies to solitary consonants $(t(41)=3.78, p<0.01)$ as well as to consonant clusters $(t(41)=6.50$, $p<0.01)$. In spelling there is no difference between prevocalic and postvocalic solitary consonants; the spelling of both types is near ceiling level (16). Spelling prevocalic consonant clusters again is easier than spelling postvocalic clusters $(t(41)=5.90, p<0.01)$. The facilitating effect of spelling indeed appears to be larger for the postvocalic consonants: There is no significant segmentation-spelling difference for solitary prevocalic consonants, nor for prevocalic consonant clusters, but such a difference is found for single postvocalic consonants $(t(41)=3.14, p<0.01)$ as well as for postvocalic consonant clusters $(t(41)=2.29$, $p<0.05$ ), with spelling being easier than segmentation.

Our data agree with the assumption that the benefit of writing down the segmentation products lies in diminishing memory load, but they do not prove it because a third explanation is also in accordance with these results. Writing down the segmentation products creates an easy opportunity to check and improve on them by reading, locally repairing, and rereading their permanent representation. In the segmentation task, however, checking has to be done on the rapidly deteriorating contents of working memory, and repairing can almost never be done locally. This explanation also predicts a positive effect of spelling where segmentation errors are most frequent - that is, at the end of a word.

More detailed information about the facilitating effects of spelling can perhaps be obtained by looking for differences in spelling accuracy in relation to the type of segmentation error. Table 2 gives examples of each segmentation error type, and the number of correct spellings per segmentation error type for prevocalic and postvocalic consonant clusters separately. The analysis is restricted to consonant clusters, because the spelling of solitary consonants was

Table 2. Types of segmentation errors in consonant clusters, their frequency of occurrence, and the frequency with which corresponding spellings were correct

\begin{tabular}{|c|c|c|c|}
\hline Segmentation-error type & $\begin{array}{l}\text { Example: } \\
\text { fits [flash] }\end{array}$ & $\begin{array}{l}\text { Frequency of } \\
\text { incorrect } \\
\text { segmentation }\end{array}$ & $\begin{array}{l}\text { Frequency of } \\
\text { correct spelling }\end{array}$ \\
\hline \multicolumn{4}{|l|}{ Prevocalic consonant clusters } \\
\hline Deletion of first consonant & $l-i-l-s$ & 0 & - \\
\hline Deletion of second consonant & $f-i-i-s$ & 21 & 4 \\
\hline Nonsegmentation of cluster & $f-i-t-s$ & 28 & 20 \\
\hline \multicolumn{4}{|l|}{ Nonsegmentation of } \\
\hline second consonant and vowel & $f-l i-l-s$ & 1 & 1 \\
\hline Substitution of one consonant & $g-l-i-t-s$ & 1 & 1 \\
\hline Wrong order of consonants & $l-f-i-t-s$ & 0 & - \\
\hline More than one error & $r i-t-s$ & 1 & 1 \\
\hline Total & & 52 & 27 \\
\hline \multicolumn{4}{|l|}{ Postvocalic consonant clusters } \\
\hline Deletion of first consonant & $f-l-i-s$ & 51 & 12 \\
\hline Deletion of second consonant & $f-l-i-t$ & 17 & 10 \\
\hline Nonsegmentation of cluster & $f-l-i-t s$ & 39 & 20 \\
\hline \multicolumn{4}{|l|}{ Nonsegmentation of } \\
\hline vowel and first consonant & $f-l-i t-s$ & 100 & 31 \\
\hline Substitution of one consonant & $f-l-i-p-s$ & 4 & 3 \\
\hline Wrong order of consonants & $f-l-i-s-l$ & 11 & 5 \\
\hline More than one error & $f-l-i s$ & 33 & 12 \\
\hline Total & & 255 & 93 \\
\hline
\end{tabular}


almost perfect. The discussion will be limited to the most frequent types of segmentation errors: nonsegmentations and deletions. Beforehand, the question will be considered why segmentation of postvocalic consonant clusters is more difficult than segmentation of prevocalic consonant clusters.

Nonsegmentation of the prevocalic consonant and vowel almost never occurs whereas nearly $40 \%$ of the segmentation errors involving postvocalic consonant clusters consists of nonsegmentation of the vowel and the postvocalic consonant. These nonsegmentations of vowel and postvocalic consonant would be predicted by the onset-rime distinction (Treiman, 1985a). Spoken syllables seem to contain two major units: an optional onset (initial consonant or cluster, such as $h$ - or $f$-) and an obligatory rime (the vowel and any following consonants, such as -alf and -its). Whereas the prevocalic consonant and the vowel are separated by the onset-rime boundary, the vowel and the postvocalic consonant are tied together within the rime, Segmentation effects that are predicted by the onset-rime distinction have been reported before (e.g., Bruck \& Treiman, 1990; Schreuder \& van Bon, 1989).

That the consonant next to the vowel is more often deleted in postvocalic ( 51 times) than in prevocalic positions ( 21 times) is also in accordance with the onset-rime distinction; in the postrocalic position the consonant is embedded in the rime and in the prevocalic position it has a more distinct position at the outside of the onset.

The two largest categories of segmentation errors involving postvocalic consonants thus can be explained by the onset-rime structure of the syllable. This structure does not account, however, for all of the differences observed in the segmentation of prevocalic and postvocalic ciusters. All types of segmentation errors are more frequent in postvocalic than in prevocalic positions. The last consonant of a word is more often omitted than the first. The postvocalic consonant cluster is more often left unsegmented than the prevocalic cluster. Postvocalic consonant substitutions and transpositions are more ferequent than prevocalic ones. Evidently there are other factors, apart from the internal structure of the syllable, that make phonemes later in the syllable more difficult to segment. One such factor would be the increased memory load mentioned earlier.

A comparatively high percentage, $69 \%$, of the many nonsegmentations of vowel and postvocalic consonant is associated with spelling errors. The percentage of incorrect spellings associated with deletions of the first postvocalic consonant is even higher, $77 \%$, which suggests that these segmentation errors, which may be conditioned by the onset-rime structure, are mostly valid indications of the phonological insight that the child brings to the spelling task, as these errors apparently only partially can be overcome by the facilitating aspects of writing. In contrast, some segmentation error categories that cannot be tied to the onset-rime distinction show a lower percentage of spelling errors: nonsegmentation of a postvocalic consonant cluster (49\%), or deletion of a second postvocalic consonant (41\%). These errors seem to be produced by task demands that are specific to the segmentation test. The few correct spellings in the case where the consonant preceding the vowel was deleted (19\%), however, suggest that it is not only onset-rime effects that make for segmentation errors with their counterparts in spelling. Interpretation in terms of the onset-rime structure of the syllable is furthermore complicated by the high percentage of correct spellings associated with the nonsegmentation of initial clusters, since they suggest that subjects tend to answer with whole onsets in the segmentation task only.

A fourth explanation should be mentioned that concerns the nonsegmentations. The need to represent a speech sound by a grapheme asks for more accurate segmentation in grapheme-by-grapheme spelling. Answering with an unanalyzed part of the word in a segmentation test, for instance segmenting fits [flash] as $f-i-t-s$ does not provide feedback about the accuracy of the response. In the grapheme-by-grapheme spelling of this word, 
however, no phoneme-to-grapheme conversion rule appears to apply to a fragment like $f$, and the child might therefore be stimulated to reconsider the segmentation of that word. It cannot be ruled out, however, that the subjects used multiphoneme/multigrapheme correspondence rules. One type of such multigrapheme units to represent multiphoneme units might be high frequency function words like en [and], in [in] and al [already] in writing mens, prins and half. Using such unanalyzed wholes would lead to errors in the segmentation task, but not in the spelling task. Unanalyzed fragments of this kind are indeed found in the segmentation responses for a few items, but the number of unexpected correct spellings is not higher for these words.

As stated before, a number of findings here is in accordance with the hypothesis that segmentation underlies spelling performance. That some words are difficult to segment but nevertheless written correctly does not necessarily mean that they are not written on the basis of a specification of their phonological units. Some of the explanations offered above suggest that spelling entails segmentation into phonological units and that segmentation can be made easier (and more accurate) by writing down these units. These explanations, however, raise doubts about the degrees to which the segmentation task actually reflects the way in which a child segments a word when spelling.

The test-retest reliability proved to be high for the segmentation test $(0.92)$ as well as for the spelling test (0.87). As stated before, however, no conclusions can be drawn from this figure about the stability of the segmentation at the item level. As we have seen, $13 \%$ of the words were segmented correctly on one occasion and incorrectly on another. This percentage only gives a lower limit for the discrepancies between two occasions for even if a word is segmented incorrectly on both occasions the two segmentations need not be the same. Twenty-one percent of the words were incorrectly segmented on both occasions. In 156 ( $55 \%)$ of these 285 cases the segmentations were precisely the same. Figures for the spelling test were comparable. Test-retest reliability may appear to be high, but $17 \%$ of the words were spelled correctly at one occasion and incorrectly on the other occasion. Of the 217 words that were spelled incorrectly on both occasions only $132(61 \%)$ were segmented in exactly the same way. These findings suggest that not only the way in which a word is segmented in a segmentation task, but also the conception of the phonological word structure or other knowledge that is used in spelling is unstable to a certain degree.

Our finding that spelling sometimes is easier than segmentation, could be typical for poor spellers only, who have perhaps over time developed an idiosyncratic way of spelling (Frith, 1985). The earlier pilot study with beginning readers/writers (Duighuisen et al., 1990), however, suggests that this is not the case. Moreover, the findings of a recent study comparing the segmentation and spelling of monosyllabic words containing one or two CC clusters in first-graders after two to four months of literacy education (Duighuisen \& van Bon, 1992) on the whole agree with those of the current experiment. The results for these beginning spellers generally did not differ from those in the current study. Both experiments found almost equal segmentation-spelling correlations: 0.74 (beginning spellers) and 0.73 (poor spellers). Just as for the poor spellers, spelling words containing consonant clusters proved to be more difficult for the beginning spellers than segmenting them, and the speling-segmentation difference proved to be larger for postvocalic than for prevocalic consonant clusters. This suggests that the relation between segmentation and spelling may be the same for both groups. However, differences between the groups were also found. One example is that there was a spelling-segmentation difference on initial consonant clusters for beginning spellers but not for poor spellers. Another example is the finding that poor spellers write better with initial consonant clusters than with final consonant clusters while no such difference was found for beginning spellers. Although beginning spellers too tended to nonsegment the vowel and the following 
consonant and to omit the first postvocalic consonant, only beginning spellers failed to segment prevocalic consonant clusters and showed a tendency to delete the consonants preceding the vowels. In poor as well as in beginning spellers only few unexpected correct spellings were found for deletions of the last consonant before the vowel, but poor spellers produced more incorrect spellings for nonsegmentations of the vowel and the first postvocalic consonant or for deletions of that consonant. One is tempted to interpret these findings as indicative of different processing strategies. For instance, the poor spellers produced a smaller percentage of unexpected postvocalic consonant cluster spellings than the beginning spellers ( 36 vs. $39 \%, t(140)=2.91, p<0.01$ ), with the error patterns suggesting that poor spellers have larger problems breaking up rimes and therefore are often unaware of the first postvocalic consonant. It must be noted, however, that an interpretation in terms of processing differences is precarious at best because the words used with the beginning spellers differed from those used with the poor spellers, and the spelling levels of the two groups differed slightly. Although the central findings appear to be robust, independent studies comparing poor and beginning spellers should be undertaken.

Our finding that sometimes spelling is easier than phonemic segmentation, does not force us to exclude phonological decomposition from our conception of the spelling process, for the relative surplus of correct spellings may reflect aspects of spelling that facilitate segmentation during spelling and therefore improve performance. This line of reasoning implies, however, that the validity of a phonemic segmentation test for investigating the segmentation that underlies phonological spelling, is limited. A segmentation task of the type employed in this experiment evidently does not provide the specifics of the phonological structure that the child has at its disposal when writing a word. It should, for this reason, not be concluded from imperfect segmentation performance, either at the test or at the item level, that the phonological basis for spelling is somehow lacking. Such a conclusion requires confirmation by the presence of corresponding spelling errors at least. When the child's conception of a word's phonological structure appears to be inadequate, moreover, it should be recognized that training directed purely at the auditory and articulatory characteristics of the spoken word may be more complicated and demanding than is necessary for the actual act of spelling, which is corroborated by the findings that segmentation learning is facilitated by the use of letters (Bradley \& Bryant, 1983; Hohn \& Ehri, 1983).

\section{REFERENCES}

Beers, J. W. (1980) Developmental strategies of spelling competence in primary school chiidren. In E. H. Henderson \& J. W. Beers (Eds.), Developmental and cognitive aspects of learning to spell (pp. 36-45). Newark, DE: International Reading Association.

Bradley, L. \& Bryant, P. (1983). Categorizing sounds and learning to read: A causal connection. Nature, 301, 419-421.

Bruck, M. \& Treiman, R. (1990). Phonological awareness and spelling in normal children and dyslexics: The case of initial consonant clusters. Journal of Experimental Child Psychology, 50, 156-178.

Calfee, R. C., Lindamood, P. \& Lindamood, C. (1973). Acoustic-phonetic skills and reading, kindergarten through twelfth grade. Journal of Educational Psychology, 64, 293-298.

Cataldo, S. \& Ellis, N. (1988). Interactions in the development of spelling, reading and phonological skills. Journal of Research in Reading, 11, 86-109.

Chomsky, C. (1979). Approaching reading through invented spelling. In L. Resnick \& P. A. Weaver (Eds.), Theory and practice of early reading. Vol. 2, (pp. 43-65). Hillsdale, NJ: Eribaum.

Coltheart, M. (1978). Lexical Access in Simple Reading Tasks. In G. Underwood (Ed.), Strategies of Information Prcoessing (pp. 151-216). London: Academic Press.

Duighuisen, H. C. M., Kerstholt, M. T. \& van Bon, W. H. J. (1990). De relatie tussen fonemische segmentatie en spellen [The relation between phonemic segmentation and spelling]. In A. Pennings, 
A. van der Leij, W. Meeus, B. Rang \& Th. Wubbels (Eds.), Bijdragen aan pedagogisch onderzoek 1990 (pp. 211-212). Leuven-Amersfoort: ACCO.

Duighuisen, H. C. M. \& van Bon, W. H. J. (1992). Spellen is onverwacht gemakkelijker dan segmenteren [Spelling is unexpectedly easier than segmentation]. Stem, Spraak-en Taalpathologie, $1,137-149$.

Ehri, L. C. \& Wilce, L. S. (1980). The influence of orthography on readers' conceptualization of the phonemic structure of words. Applied Psycholinguistics, 1, 371-385.

Ellis, A. W. (1984). Reading, writing and dyslexia. London: Lawrence Erlbaum.

Fox, B. \& Routh, D. K. (1975). Analyzing spoken language into words, syllables, and phonemes: A developmental study. Joumal of Psycholinguistic Research, 4, 331-342.

Frith, U. (1985). Beneath the surface of developmental dyslexia. In K. Patterson, M. Coltheart \& J. Marshall (Eds.) Surface dyslexia. London: Erlbaum.

Gussenhoven, C. \& Bremmer, R. H. (1983). Voiced fricatives in Dutch: Sources and present-day usage. North-Western Language Evolution, 2, 55-71.

Helfgott, J. A. (1976). Phonemic segmentation and blending skills of kindergarten children: Implications for beginning reading acquisition. Contemporary Educational Psychology, 1, 157-169.

Hohn, W. E. \& Ehri, L. C. (1983). Do alphabet letters help prereaders acquire phonemic segmentation skill? Joumal of Educational Psychology,, 75, 752-762.

Liberman, L. Y. (1973). Segmentation of the spoken word and reading acquisition. Bulletin of the Orton Society, 23, 65-77.

Lundberg, I., Olofsson, A. \& Wall, S. (1980). Reading and spelling skills in the first school years predicted from phonemic awareness skills in kindergarten. Scandinavian Journal of Psychology, 21, $159-173$.

Mann, V. A., Tobin, P. \& Wilson, R. (1987). Measuring phonological awareness through the invented spellings of kindergarten children. Merrill-Palmer Quarterly, 33, 365-391.

Marsh, G., Friedman, M. P., Welch, V. \& Desberg, P. (1980). Development of strategies in spelling. In U. Frith (Ed.), Cognitive processes in spelling (pp. 339-353). London: Academic Press.

Perfetti, C. A., Beck, I., Bell, L. \& Hughes, C. (1987). Phonemic knowledge and learning to read are reciprocal: A longitudinal study of first grade children. Merrill-Palmer Quarterly, 33, 283-319.

Perin, D. (1983). Phonemic segmentation and spelling. British Journal of Psychology, 74, 129-144.

Read, C. (1971). Preschool children's knowledge of English phonology. Harvard Educational Review, 41, $1-34$.

Read, C. (1986). Children's creative spellings. London: Routledge \& Kegan Paul.

Reitsma, P. (1983). Phonemic and graphemic codes in learning to read. Unpublished doctoral dissertation.

Schreuder, R. \& van Bon, W. H. J. (1989). Phonemic analysis: Effects of word properties. Journal of Research in Reading, 12, 59-78.

Stanovich, K. E., Cunningham, A. E. \& Cramer, B. B. (1984). Assessing phonological awareness in kindergarten children: Issues of task comparability. Journal of Experimental Child Psychology, 38, $175-190$.

Staphorsius, G., Krom, R. S. H. \& Geus, K. de (1989). Frequenties van Woordvormen en Letterposities in Jeugdlectuur. Arnhem: Cito.

Treiman, R. (1985a). Phonemic analysis, spelling and reading. In T. Carr (Ed.), New directions for child development: The development of reading skills (pp. 15-18). San Francisco: Jossey-Bass.

Treiman, R. (1985b). Phonemic awareness and spelling: Children's judgements do not always agree with adults'. Journal of Experimental Child Psychology, 39, 182-201.

Tunmer, W. E. \& Nesdale, A. R. (1982). The effects of digraphs and pseudowords on phonemic segmentation in young children. Applied Psycholinguistics, 3, 299-311.

van Heuven, V. J. (1980). Aspects of Dutch orthography and reading. In J. F. Kavanagh \& R. L. Venezky (Eds.), Orthography, reading and dyslexia (pp. 57-73). Baltimore: University Park Press.

Verhoeven, L. T. W. (1980a). Woorddicte I. Arnhem: Cito.

Verhoeven, L. T. W. (1980b). Woorddicte 2. Arnhem: Cito.

Wimmer, H. \& Hummer, P. (1990). How German-speaking first graders read and spell: Doubts on the importance of the logographic stage. Applied Psycholinguistics, 11, 349-368.

Yopp, H. K. (1988). The validity and reliability of phonemic awareness tests. Reading Research Quarterly, 23, 159-177. 


\section{APPENDIX}

Words used in the experiment

CVC: lol [fun], nek [neck], boot [boat], pas [passport], gum [eraser], zeep [soap], raaf [raven], fit [fresh]

CVCC: rots [rock], kist [box, crate], damp [steam], mens [human being], half [half], munt [coin], taart [cake], werp [throw]

$\operatorname{CCV}(\mathrm{C})$ : fles [bottle], trom [drum], steen [stone], prop [ball, wad], twee [two], klaar [ready], spuug [spittle], slik [swallow]

CCVCC: flits [flash], troost [comfort], stomp [punch], prins [prince], twaalf [twelve], klant [client], sport [sport], slurp [slurp]

*Italicized items are not contained in Staphorsius et al. (1989). 